
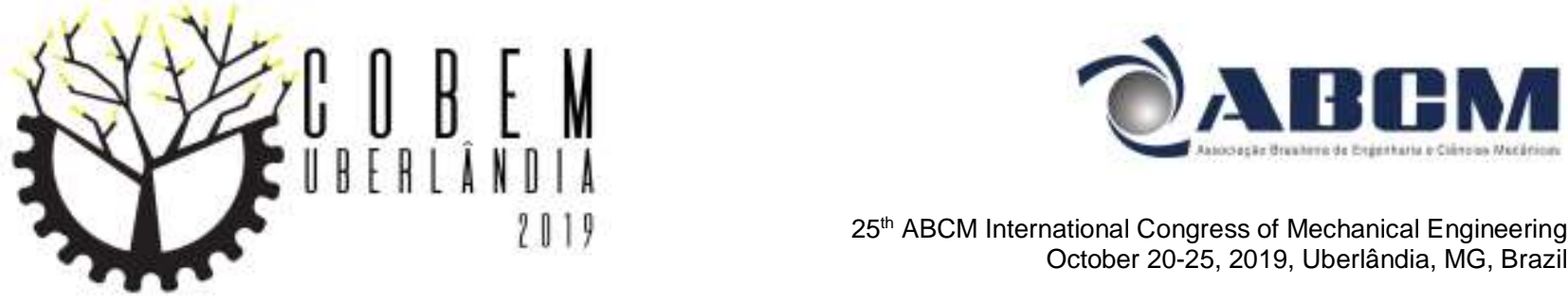

$25^{\text {th }}$ ABCM International Congress of Mechanical Engineering October 20-25, 2019, Uberlândia, MG, Brazil

\title{
COB-2019-COBEM2019-2032 \\ CHARACTERIZATION OF BIO-OIL DERIVED FROM CATALYTIC SLOW PYROLYSIS OF SUGARCANE BAGASSE
}

\author{
Bruna de Jesus Bueno Machado \\ Claudinei Henrique Ferreira Rodrigues \\ Carlos Manuel Romero Luna \\ José Claúdio Caraschi
}

UNESP - São Paulo State University, Campus of Itapeva, Rua Geraldo Alckmin, 519, 18409-010, Itapeva-SP, Brazil. bru.bueno@unesp.br;claudinei.hr7@gmail; carlos.romero-luna@ unesp.br; j.caraschi@unesp.br

\section{Gretta Larisa Aurora Arce Ferrufino \\ Fábio Roberto Vieira}

Ivonete Ávila

UNESP - São Paulo State University, Guaratinguetá Engineering Faculty, Department of Energy, Combustion and Carbon Capture Laboratory (LC3), Av. Dr. Ariberto Pereira da Cunha, 333, 12.516-410, Guaratinguetá-SP, Brazil.

gretta.arce@unesp.br; fabio.r.vieira@unesp.br; ivonete.avila@unesp.br

\section{Adriana da Silva}

INPE - Institute for Research Space, Propulsion and Combustion Laboratory, Rodovía Presidente Dutra, km 40, 12630000, Cachoeira Paulista - SP - Brazil.

adriana.silva@inpe.br

Abstract. Emissions of greenhouse gases (GHGs) and other pollutants have increased considerably over the past decades due to the continued use of energy derived from fossil fuels. This has led to problems and environmental impacts that motivate the use of clean and renewable energy sources and unconventional combustion processes. Biomass is a renewable source and has great potential for CO2 neutral energy generation. Among all the alternatives for the use of biomass, thermochemical conversion processes are the most efficient, and pyrolysis is the process capable of producing biofuels, minimizing dependence on fossil fuels. The most studied types of pyrolysis are: rapid pyrolysis and slow pyrolysis. The slow pyrolysis of biomass is mainly intended to produce biochar; however, a fraction of bio-oil is obtained, which presents a high content of oxygenated components, receiving less attention being discarded as residue. Several studies have highlighted the use of catalysts to improve biochar and bio-oil quality. However, it is noteworthy that the literature presents few studies regarding the effect of the use of catalysts in the slow pyrolysis of biomass. In Brazil, sugarcane is an important energy crop used for ethanol production, thereby, large quantities of sugarcane bagasse are generated. Nowadays there are many alternatives for use this resource, one of them is pyrolysis. In literature, several works have studied the fast pyrolysis of sugarcane bagasse for biofuel production, however, the possibility of obtaining bio-oil through slow pyrolysis has not yet been studied. Thus, the objective of this work is to study the catalytic slow pyrolysis of sugarcane bagasse for bio-oil production.

Keywords: Catalytic slow pyrolysis, calcium oxide, sugarcane bagasse, bio-oil.

\section{INTRODUCTION}

Currently, 80-85\% of the world's energy demand is supplied mainly by fossil fuels such as coal, oil and natural gas. The constant use of fossil fuels generates large amounts of greenhouse gases (GHG) to the atmosphere (Abbasi and Yozgatlilgil 2014; Saidur et al., 2011). Of the total GHG emitted, 3/4 correspond to carbon dioxide (CO2) which is the main anthropogenic emission responsible for global warming (Huaman and Jun 2014; Lin et al., 2011). According to the Intergovernmental Panel on Climate Change (IPCC, 2013), there is a direct correlation between rising GHGs and global warming. To meet the high energy demand aiming at the reduction of GHG emissions, mainly CO2, several alternatives were proposed, among them the use of biomass. Biomass is the fourth largest source of energy in the world and has been found to be a potential source of renewable energy, since it can simultaneously solve the problems of energy demand and chemical production (Saidur et al., 2011; Tinwala et al. al., 2015, Kim et al., 2017). Biomass utilization can be achieved through biochemical and thermochemical conversion methods. However, thermochemical 
conversion has received increased attention because of its rapidity and greater efficiency when compared to biochemical conversion (Tripathi et al., 2016).

Among all thermochemical processes, pyrolysis has the potential to produce biofuels with a high energy density from non-food resource sources (agricultural, urban, industrial and animal waste) (Demiral and Sensöz 2006). According to Kabir and Hameed (2017), pyrolysis using lignocellulosic biomass not only produces renewable but also petrochemical fuels; consequently, this can minimize dependence on fossil fuels. Biomass pyrolysis is the process of thermal decomposition in an inert medium which result in three products: a solid (biochar), a liquid (bio-oil) and a gas (pyrolytic gas) (Demiral and Sensöz 2006; Tripathi et al. al. 2016). Among the most studied types of pyrolysis are rapid pyrolysis and slow pyrolysis.

Slow pyrolysis of biomass is primarily intended to produce biochar (Russell et al., 2017). Biochar may have several applications, such as in agriculture, water treatment and catalytic chemical processes (Tan et al., 2015, Lee et al., 2017). In the slow pyrolysis process, biochar is the dominant product fraction, however, a significant fraction of bio-oil and a lower fraction of pyrolytic gas are also produced. Diverse studies have shown that the bio-oil and pyrolytic gas fractions produced by the pyrolysis process can be used as a source of heat in the process, reducing the cost of processing (Park et al., 2014; Dunningan et al., 2016). Depending on the type of biomass and operating conditions, the bio-oil produced presents a considerable content of oxygenated components, therefore receives less attention (due to the low HHV) being discarded as waste (Kabir and Hameed 2017).

On the other hand, based on the experience obtained in the production of bio-oil by rapid catalytic pyrolysis, there is a great interest in the use of catalysts in the slow pyrolysis of biomass since it can increase the productivity of the biochar, and the quality of the bio-oil produced (Russell et al., 2017). Thus, both products (i.e., biochar and bio-oil) could be used as the chemical base for the synthesis of other products or as an energy source, improving the yield of this process.

Currently, the literature presents several papers that discuss the study of the slow thermal pyrolysis of several biomasses, however, there are few studies regarding the effect of the use of catalysts in the process of slow pyrolysis of biomass. This work to study the effect of adding a catalyst $(\mathrm{CaO})$ on the yield of slow pyrolysis of sugarcane bagasse and into properties of their products.

\section{MATERIALS AND METHODS}

\subsection{Materials}

Figure 1a shows a sample of sugarcane bagasse in natura. For experimental test a sample of sugarcane bagasse was milled until a particle size of $200 \mu \mathrm{m}$. This granulometry was selected to get an appropriate mixing with the catalyst.

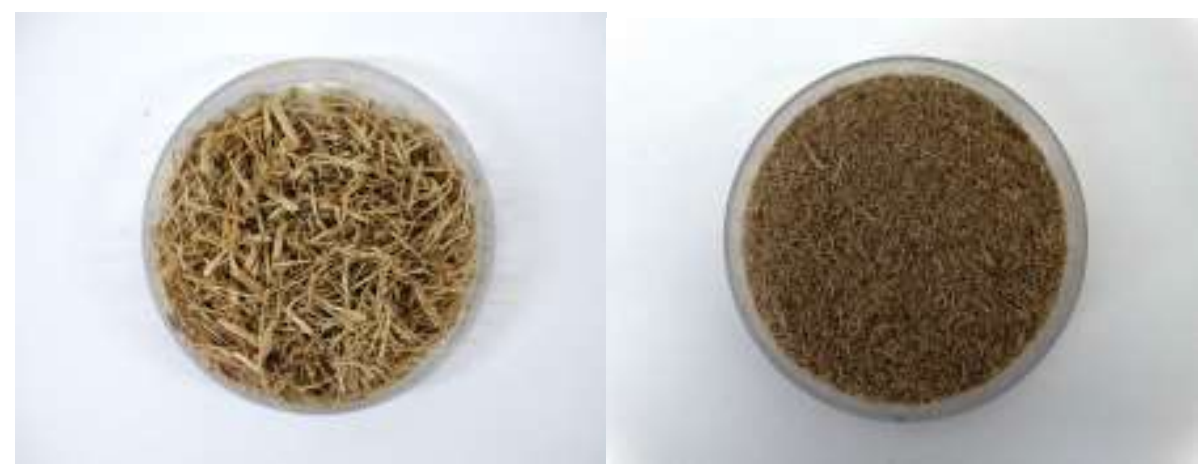

Figure 1. (a) Sugarcane bagasse (a) in natura; (b) particle size on range of $250-500 \mu \mathrm{m}$.

\subsection{Experimental setup}

Figure 2 exhibit the experimental setup used for the test. For experimental test was considered a temperature of $400^{\circ} \mathrm{C}$. The mass fractions of catalyst used are $10 \% ; 20 \%$, and $30 \%$. In all experiments the mass of biomass was $20 \mathrm{~g}$. The catalyst (calcium oxide) was previously mixed with biomass being a IN-SITU catalyst pyrolysis. A flow rate of $100 \mathrm{ml}$ of nitrogen gas is used to carrier the material volatile. 


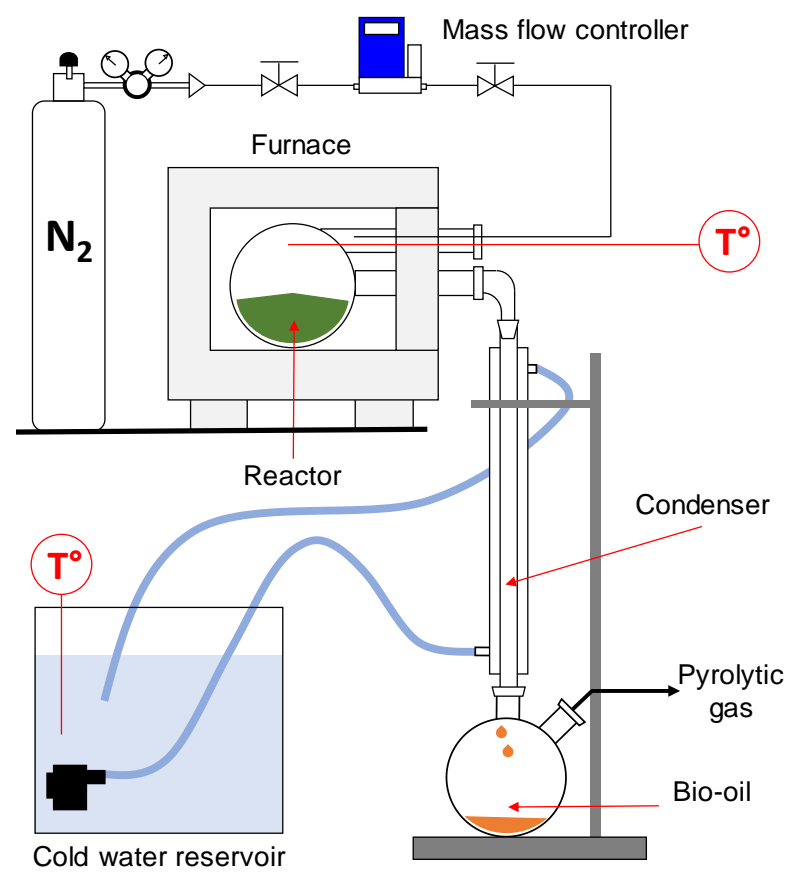

Figure 2. Experimental setup of the catalytic slow pyrolysis.

\subsection{Characterization techniques}

In this section is showed the techniques used for characterization of products. TGA analysis was performed by TA Instruments (SDT Q600) in duplicate using a mass of $10 \pm 0.5 \mathrm{mg}$, a heating rate of $10^{\circ} \mathrm{C} / \mathrm{min}$ and an inert atmosphere of nitrogen. HHV was determined using a Calorimeter IKA C500. All tests are performed in duplicate using a mass of $(0.5 \pm 0.05) \mathrm{g}$. FTIR analysis was performed in a Perkin Elmer Spectrum $100 \mathrm{FTIR} / \mathrm{ATR}$ analyzer to measure the emission of absorption and diffusion of an infrared spectrum into the sample. A pH meter model 522 of MS Tecnopon equipment was used to determine the $\mathrm{pH}$ of the samples.

\section{RESULTS AND DISCUSSION}

Figure 3 shows three mass loss peaks that are characteristic of lignocellulosic materials. The first mass loss event refers to the loss of moisture $\left(53^{\circ} \mathrm{C}\right)$. The second and third events refer to the decomposition of hemicellulose, cellulose, and lignin, and depending on the temperature each of these elements dominates the rate of decomposition. In the second event $\left(293{ }^{\circ} \mathrm{C}\right)$ the hemicellulose decomposition is initially dominant, but the lignin also decomposes at this temperature. The third mass loss $\left(354^{\circ} \mathrm{C}\right)$ is mainly related to cellulose decomposition, and at the end of the event lignin begins to dominate the rate of mass loss and continues to decompose above $400{ }^{\circ} \mathrm{C}$.

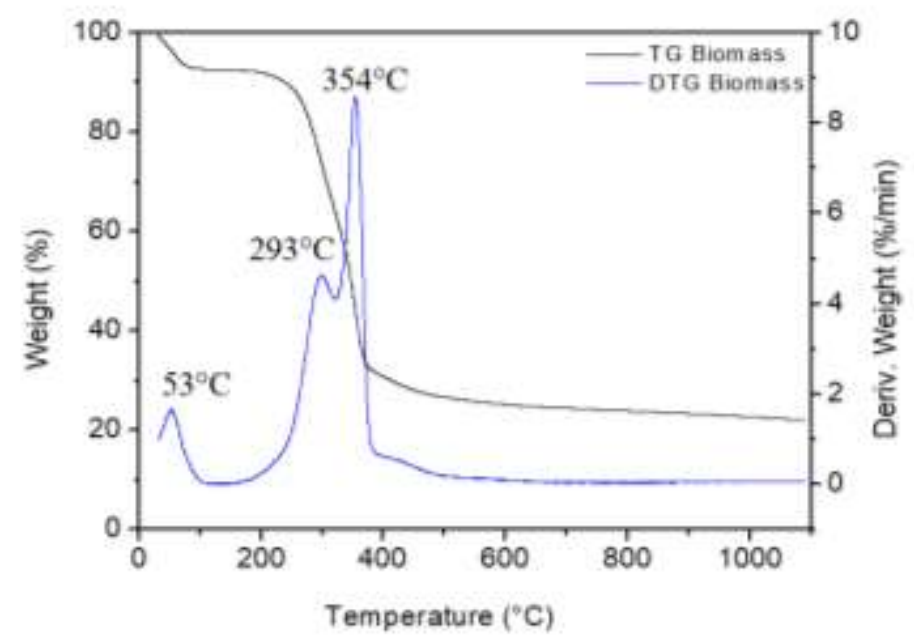

Figure 2. TG and DTG curves of sugarcane bagasse. 
Figure 3 shows the products yield obtained in all conditions studied in this work. Without catalyst is the reference condition (41\% biochar, $49 \%$ bio-oil and $10 \%$ pyrolytic gas). It can be observed that as the catalyst concentration increases there is a progressive reduction in the bio-oil yield. The biochar content increases considerably due to the increased catalyst content, however, when it is used $10 \%$ of catalyst, it can be observed a reduction of biochar yield which show an additional decomposition of biomass cause an increased pyrolytic gas yield. Using 20\% and 30\% of catalyst the pyrolytic gas yield is almost constant, however, the bio-oil continues reducing.

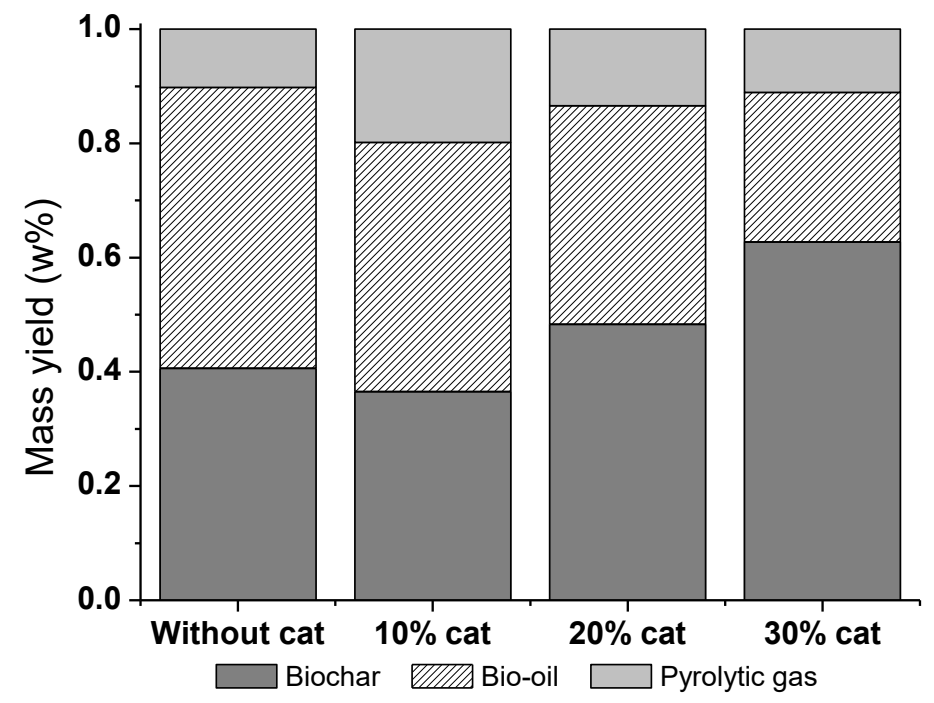

Figure 3. Products yield from pyrolysis conditions.

Figure 4 exhibit the bio-oil obtained from the experimental test. In all conditions that used catalyst observed a clarification of bio-oil color (Figures $4 \mathrm{a}$ and $4 \mathrm{~b}$ ). Besides that, it was visualized a strong smell of volatile product.

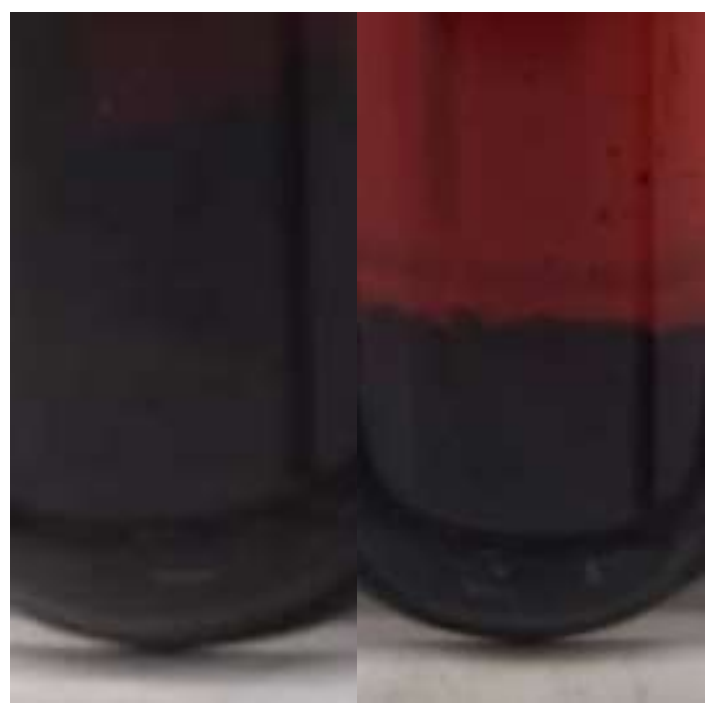

(a)

(b)

Figure 3. Bio-oil from sugarcane (a) without catalyst and (b) with catalyst.

Table 1 shows that bio-oil in all condition has an acidic $\mathrm{pH}$ on range of $3-4.5$, however, as the catalyst content increases the $\mathrm{pH}$ value increases. The use of catalyst can somehow improve the conditions of the bio-oil, aiming its use as a fuel. A reduction of $\mathrm{pH}$ could be attributed to the reaction between calcium oxide and organic acids, for example, calcium reacting with acetic acid can be form calcium acetate. 
Table 1. $\mathrm{pH}$ values of bio-oil.

\begin{tabular}{|c|c|}
\hline & $\mathrm{pH}$ \\
\hline Without cat. & 3 \\
\hline $10 \%$ cat. & 3 \\
\hline $20 \%$ cat. & 4 \\
\hline $30 \%$ cat. & 4,5 \\
\hline
\end{tabular}

Figure 4 shows the FTIR spectra of bio-oil from pyrolysis of sugarcane bagasse. It can be observed a chance of chemical composition of bio-oil by using of catalyst $(\mathrm{CaO})$. An increase of catalyst has no significant chance on chemical composition of bio-oil.

The peak at $3395 \mathrm{~cm}^{-1}$ is related to $\mathrm{O}-\mathrm{H}$ stretching vibration that was caused by water or alcohol in the bio-oil. The peak at $2928 \mathrm{~cm}^{-1}$, which may attribute to $\mathrm{C}-\mathrm{H}$ stretching, by presence of alkyl C-H. The $\mathrm{C}=\mathrm{O}$ stretching vibration at $1705 \mathrm{~cm}^{-1}$ indicate the presence of ketones, aldehydes, esters or acids. The peak at $1367 \mathrm{~cm}^{-1}$ indicate the presence of alkanes by $\mathrm{C}-\mathrm{H}$ bending vibrations. The peak at $1514 \mathrm{~cm}^{-1}$ indicate the presence of alkenes by $\mathrm{C}=\mathrm{C}$ skeletal vibration. The bands at 1232, 1115 and $1021 \mathrm{~cm}^{-1}$ are related to $\mathrm{C}-\mathrm{O}$ stretching vibration, showing possible existence of acids or alcohols in the bio-oil.

The use of the catalyst causes a uniformity of the spectrum, indicating a regularization in the chemical composition. There is a significant increase in the band corresponding $\mathrm{O}-\mathrm{H}$ stretching vibration caused by water or alcohol. There are no significant differences among the FTIR spectra of bio-oil using catalyst.
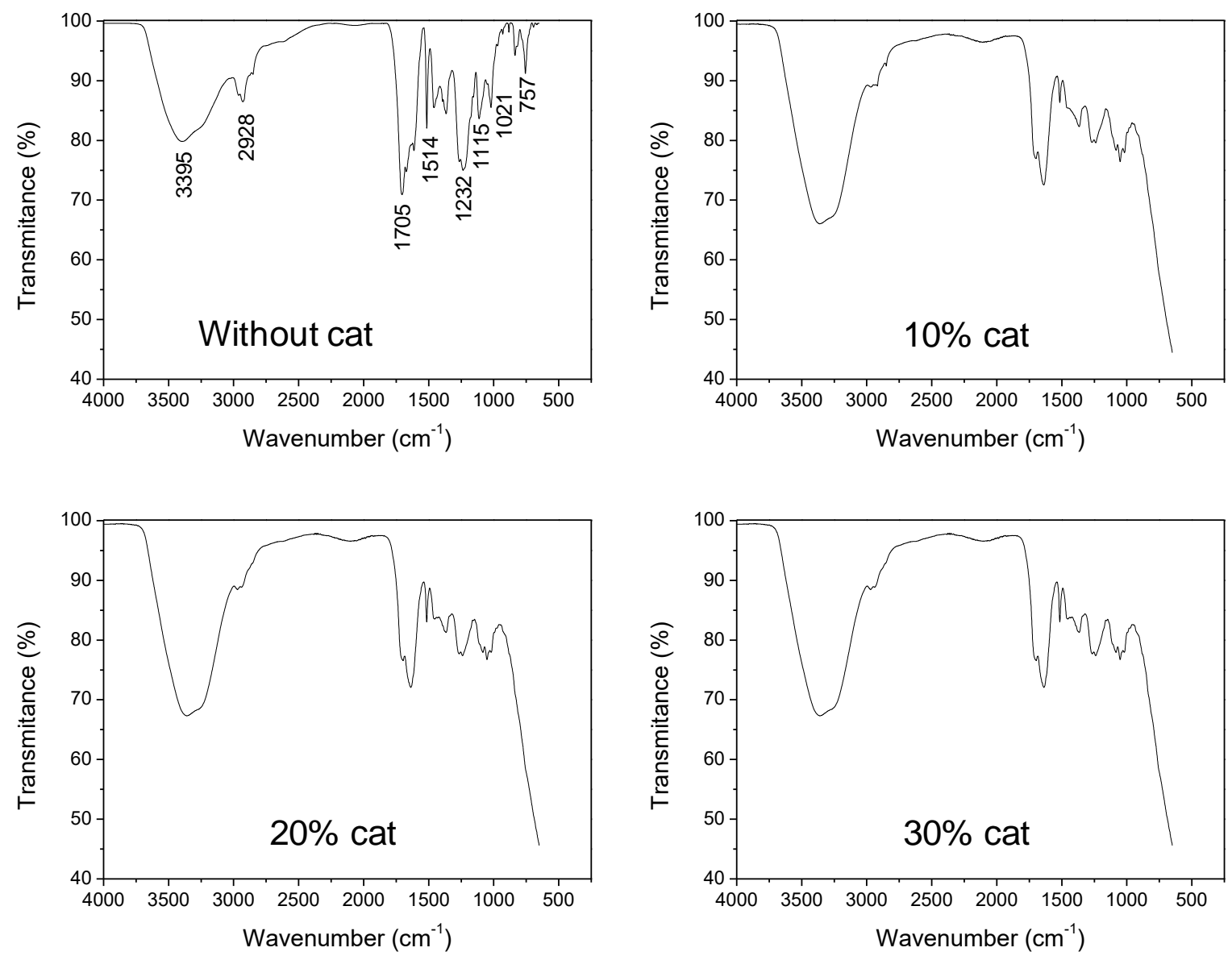

Figure 4. FTIR spectra of bio-oil from sugarcane without catalyst and using catalyst.

\section{CONCLUSIONS}

The results show an increase of yield of biochar and a reduction of bio-oil yield. The use of catalyst improves the quality of bio-oil. The catalyst causes a change in the composition of the bio-oil. 


\section{ACKNOWLEDGEMENTS}

The authors would like to thank the National Council for Scientific and Technological Development (CNPq) (Process - 439125/2018-9) and Coordination for the Improvement of Higher Education Personnel (CAPES) by PNPD post-doctoral fellowship.

\section{REFERENCES}

Abbasi A., E., Yozgatlilgil, A. (2014). A study on the effects of catalysts on pyrolysis and combustion characteristics of Turkish lignite in oxy-fuel conditions. Fuel, v.115, p.841-849.

Demiral, İ.; Şensöz, S., (2006). Fixed-Bed Pyrolysis of Hazelnut (Corylus Avellana L.) Bagasse: Influence of Pyrolysis Parameters on Product Yields Energy Sources, Part A Recover. Util. Environ. Eff. v.28, p.1149-1158.

Dunningan, L., Ashman, P. J., Zhang, X., Kwong, C.W., (2016) Production of biochar from rice husk - Particulate emissions from the combustion of raw pyrolysis volatiles. Journal of Cleaner Production, v.xxx, p.1-7.

Huaman, R. N. E., Jun, T. X. (2014). Energy related CO2 emissions and the progress on CCS projects: A review. Renewable and Sustainable Energy Reviews, v.31, p.368-385.

Kabir, G., Hameed, B. H. (2017). Recent progress on catalytic pyrolysis of lignocellulosic biomass to high-grade bio-oil and bio-chemicals. Renewable and Sustainable Energy Reviews, v.70, p.946-967.

Kim, E., Gil, H., Park, S., Park, J. (2017). Bio-oil production from pyrolysis of waste sawdust with catalyst ZSM-5. J. Mater Cycles Waste Manag, v.19, p.423-431.

Lee, J., Kim, K. H., Kwon, E. E., (2017). Biochar as a Catalyst, Renewable and Sustainable Energy Reviews. v.77, p.70-79.

Lin, S., Kiga, T., Wang, Y., Nakayama, K. (2011). Energy analysis of CaCO3 calcination with CO2 capture. Energy Procedia, v.4, p.356-361.

Park, J., Lee, Y., Ryu, C., Park Y. K., (2014). Slow pyrolysis of rice straw: Analysis of products properties, carbon and energy yields. Bioresource Technology, v.155, p.63-70.

Russell, S. H., Turrion-Gomes, J. L., Meredith, W., Langston, P., Snape, C.E., (2017) Increased charcoal yield and production of lighter oils from the slow pyrolysis of biomass. Journal of Analytical and Applied Pyrolysis, v.124, p.536-541.

Saidur, R., Abdelaziz, E.A., Demirbas, A. Hossain, M.S., Mekhilef, S. (2011) A review on biomass as a fuel for boilers. Renewable and Sustainable Energy Reviews, v.15, p.2262-2289.

Tan, X., Liu, Y., Zeng, G., Wang, X., Hua, X., Gu, Y., Yang, Z., (2015). Application of biochar for the removal of pollutants from aqueous solutions. Chemosphere, v.125, p.70-85.

Tinwala, F., Mohanty, P., Parmar, S., Patel, A.; Pant, K. K., (2015) Intermediate pyrolysis of agro-industrial biomasses in bench-scale pyrolyser: Product yields and its characterization. Bioresource Technology, v.188, p.258-264.

Tripathi, M., Sahu, J. N., Ganesan, P., (2016). Effect of process parameters on production of biochar from biomass waste through pyrolysis: A review. Renewable and Sustainable Energy Reviews. v.55, p.467-481.

\section{RESPONSIBILITY NOTICE}

The authors are the only responsible for the printed material included in this paper. 